\title{
Good practices in Eletronorte's Public Management aimed to reduce the number of disconnections of Transmission Lines caused by forest fires.
}

\author{
Érica Kurihara ${ }^{1 *}$ \\ ${ }^{1}$ Centrais Elétricas do Norte do Brasil (Eletronorte), Brasília, Brasil. \\ *E-mail para contato: erica.pereira@eln.gov.br
}

\begin{abstract}
Forest fires are responsible for recurrent disconnection of Eletronorte's Transmission Lines. When there is a fire on the Transmission Line, the system automatically shuts down, since the equipment has a heat sensor. Therefore, beyond the environmental impact, the fires compromise the electric energy supply and promote financial loss. In 2017, Eletronorte paid $\mathrm{R} \$ 4,220,058.21$ to the National Electric Energy Agency as penalty for energy unavailability. Thus, in order to reduce those damages, in 2018 the Company added some new guidelines to its Transmission Lines management protocol. Previously, each regional branch was responsible for its own management. As from 2018, a united and systemic coordination began. A single hired company is responsible for the easement lanes cleaning, that starts simultaneously on all Transmission Lines by the end of the rainy season in May. Eletronorte also started using its own equipment to increase the mowed area in places not covered by the out hired company's contract. There is a new detailed field inspection every June, in order to help mapping the risky areas. The results is a clear reduction of shutdowns by forest fires: 2016/ 82; 2017/135; 2018/19. The penalty paid for unavailable Transmission Line time was reduced to $\mathrm{R} \$ 17,098.23$ in 2018. Perhaps Eletronorte needs more time to assess the real effectiveness of the new actions. However, based on the available data, the current guidelines for the Transmission Lines management protocol are suffice and may need some improvement in the future.
\end{abstract}

Keywords: forest fire, transmission lines, disconnection, management, improvement 